\title{
El turismo de golf en Almería y su carácter desestacionalizador
}

\author{
María del Mar Martín García*
}

Universidad de Almería (España)

\begin{abstract}
Resumen: En este artículo se realiza un análisis del turismo de golf que recibe la provincia de Almería. Para ello se ha recogido el número de salidas de cada campo de golf de la provincia desde mayo de 2017 hasta abril de 2019 y su procedencia. El estudio de los datos muestra el crecimiento de este turismo y deja constancia de su carácter desestacionalizador. El turista procedente de Europa cuyo motivo de su viaje es jugar al golf viene en los meses de otoño e invierno, lo que convierte a la provincia de Almería en un destino receptor de turistas durante todo el año. Desde el análisis de las debilidades y fortalezas de Almería como destino de golf, se expresa la necesidad de establecer las claves para un desarrollo sostenible del turismo de golf en la provincia que sitúe a Almería como uno de los principales destinos en Europa para la práctica de este deporte.
\end{abstract}

Palabras Clave: Almería Golf; Destino turístico; Turismo sostenible; Estacionalidad; Golf.

\section{Golf tourism in Almería and its seasonality}

Abstract: This article gives an analysis of golf tourism in Almeria. The research counted number of people playing on each golf course in the Province registering them by their respective countries of residence iover the period between May 2017 and April 2019. Analysis shows how golf tourism has grown and is no longer locked by seasonality, with European tourists travelling in Autumn and Winter with this as their motivation.. This would seem to indicate that Almería could be be an all-year round tourist resort. An analysis of the strengths and weaknesses of Almeria as a golf destination shows that there is a need to promote the Province and put it on the map of golf tourism resorts in Europe.

Keywords: Golf Almeria; Tourist destination; Sustainable tourism; Seasonality; Golf.

\section{Introducción}

En la primera década del presente siglo, se ha producido en España un incremento significativo de la oferta de instalaciones de golf, con una clara vinculación a los espacios litorales, asistiendo al mayor incremento de la oferta en la historia del golf en España. Destaca Andalucía que ocupa la primera posición en número de instalaciones de golf en este país. (Ferreres, 2014).

El desarrollo del turismo de golf es una realidad incuestionable en el ámbito territorial del Mediterráneo y especialmente en las zonas áridas, debido entre otras cosas, a las características climáticas que permiten la práctica deportiva continuada sin interrupción estacional (García Lorca, 2007).

Dentro del conjunto de Andalucía, en la provincia de Almería también se asiste a este incremento de la oferta de golf, contando a día de hoy con un total de ocho campos y dos más en proyecto. Al igual que en el resto de España, este incremento de nuevas instalaciones se ha concentrado entre los años 2005 y 2009 con una clara vinculación al litoral. En Almería desde el año 2000 se han abierto 5 nuevos campos, todos en la zona del levante almeriense, más la escuela pública de golf inaugurada por la Junta de Andalucía en enero del 2017.

Esta oferta de campos de golf en Almería, sitúa a esta provincia como un destino de turismo de golf, receptor de jugadores nacionales e internacionales, cuyo motivo principal de su desplazamiento es jugar al golf. El conjunto de actividades que se generan alrededor de este deporte es lo que se conoce como el turismo de golf, una actividad cuyo valor añadido consiste en romper la estacionalidad

Universidad de Almería (España); E-mail: marmarti@ual.es; https://orcid.org/0000-0003-3842-6114 
característica del sector turístico y renovar su productividad dentro de la economía de una provincia (Centro Euromediterráneo de conocimiento, innovación y formación turística, 2007).

\section{Metodologia}

Para llevar a cabo el estudio del turismo de golf en Almería se ha utilizado un método mixto de investigación combinando la revisión documental y la recogida de datos de campo, tanto cuantitativos como cualitativos.

En cuanto a la investigación documental, se ha revisado literatura escrita relacionada con el turismo de golf, libros, revistas y prensa actual especializada en golf y en turismo, realizando diferentes tipos de búsqueda a través de bases de datos, para obtener un acercamiento a la realidad del sector del turismo de golf en España. Además se han consultados las webs de los destinos de golf cercanos, similares al destino Almería, como Costa del Sol, Costa Blanca y Murcia, junto a los portales de los organismos públicos de turismo de cada uno de esos destinos.

Para completar esta labor y obtener datos concretos sobre este turismo en Andalucía y en la provincia de Almería, se han consultado asociaciones y organismos nacionales e internacionales que realizan estudios sobre el sector o recopilan datos que se han necesitado para la investigación, como la Real Federación Española de Golf (RFEG) ${ }^{1}$ y la Real Federación Andaluza de Golf (RFAG) ${ }^{2}$, la Asociación de Campos de Golf de la Costa Blanca y Comunidad Valenciana (ACGCB), la Asociación de Campos de Golf de Costa Brava, la Asociación Española de Campos de Golf (AECG), el servicio Español Público de Empleo Estatal, la Organización Mundial de Turismo (UNWTO) ${ }^{3}$,The Royal \& Ancient Golf Club de St.Andrews (R\&A) ${ }^{4}$, el Portal de Turismo de España y la web oficial de Turismo de Andalucía. También se ha consultado un organismo internacional llamado KPMG respondiendo a las siglas de sus fundadores, que recopila y publica información golfística, accediendo a través de su página web, www.golfbenchmark.com. KPMG International es una cooperativa suiza y la entidad coordinadora de una red global de empresas independientes que posee una plataforma interactiva que proporciona a las asociaciones de golf, clubes de golf, inversores, desarrolladores y otras partes interesadas de la industria, informes sobre el sector del golf de más de 40 países europeos desde 2015. Para conocer el tráfico aéreo en la provincia se ha accedido a la publicación del informe de tránsito de AENA SME S.A., empresa pública española que gestiona los aeropuertos de interés general en España.

En cuanto a la obtención de datos, tanto cualitativos como cuantitativos, se ha establecido contacto con los responsables de los ocho campos de golf que hay en la provincia, con los responsables de seis de las nueve escuelas de golf y con la Asociación de Campos de Golf de Almería (ACGA). El contacto se ha establecido personalmente en todos los casos, teniendo así la oportunidad de obtener más información en la visita a las instalaciones mediante la observación directa. El proceso de recogida de datos se ha realizado en dos fases.

En la primera fase se llevaron a cabo entrevistas con cada uno de los responsables de las entidades detalladas, recogiendo todas sus opiniones sobre el sector, las necesidades de mejora y las perspectivas de cara al futuro, así como la información relativa al tipo de cliente que reciben, las características, su procedencia y descripción.

En la segunda fase, con el análisis de toda la información recogida, se procedió al diseño de una ficha a cumplimentar por cada campo de golf para la obtención de los datos cuantitativos y cualitativos que completaran el análisis del sector del turismo de golf en Almería. Los datos cuantitativos recogidos son las cifras de salidas al campo de golf por mes referidas a las dos últimas temporadas y su procedencia por tipo de cliente. Los datos cualitativos recogidos responden al detalle de las características del cliente que reciben, con las que hemos completado el perfil del cliente de golf en Almería. Esta ficha se envió por correo electrónico y ha sido cumplimentada por los ocho campos de la provincia.

El trabajo ha concluido con el análisis e interpretación de los resultados obtenidos, estableciendo conclusiones y líneas de trabajo que contribuyan a mejorar el desarrollo del turismo de golf en la provincia de Almería.

\section{Cifras a destacar: número de salidas}

Con el análisis de las cifras de salidas de los campos de golf de la provincia y la información recogida de los responsables de cada uno de ellos, se establece que la demanda de jugadores que reciben se divide en tres tipos de cliente: el cliente local, el cliente visitante y el cliente llamado longstay, anglicismo utilizado para referirnos al cliente cuya estancia en el destino es superior a 21 días. 
En la temporada 2018, como se refleja en la tabla 1, desde mayo de 2017 hasta abril de 2018, el total de salidas de jugadores de los 8 campos de golf de la provincia fue de 313.921 salidas. Si atendemos a la procedencia de las mismas, como vemos en el gráfico 1, el 30,47 \% corresponde al cliente local, el $56,73 \%$ al cliente visitante y el otro $12,80 \%$ al cliente longstay.

Tabla 1: $\mathrm{N}^{\circ}$ Salidas por mes temporada 2017/2018

\begin{tabular}{|c|c|c|c|c|c|c|c|c|c|c|c|c|}
\hline May & Jun & Jul & Ago & Sep & Oct & Nov & Dic & Ene & Feb & Mar & Abr & Total \\
\hline 23.373 & 17.987 & 16.296 & 19.137 & 20.578 & 35.460 & 34.581 & 22.329 & 26.308 & 28.723 & 37.574 & 31.575 & 313.921 \\
\hline
\end{tabular}

Fuente: Elaboración propia

Gráfico 1: Procedencia salidas temporada 2017/2018

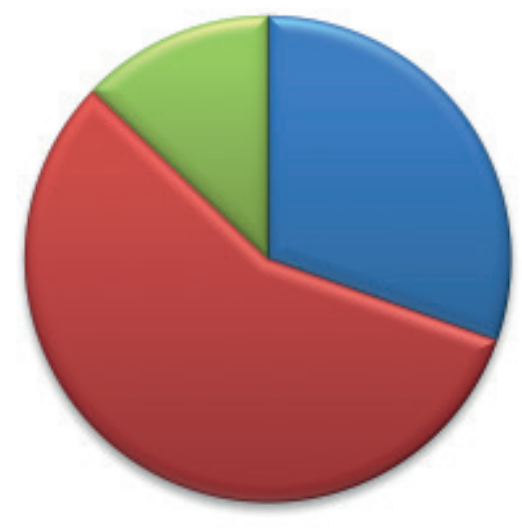

\% local

$\%$ visitante

\% longstay

Fuente: Elaboración propia

Eso traducido en número de jugadores que nos visitan, supone que llegaron a Almería alrededor de 53.756 turistas de golf procedentes de Europa, que visitaron la provincia principalmente en los meses que van desde octubre hasta abril, es decir el otoño y el invierno, tal y como muestra el gráfico 2.

Gráfico 2: Numero de salidas temporada 2017/2018

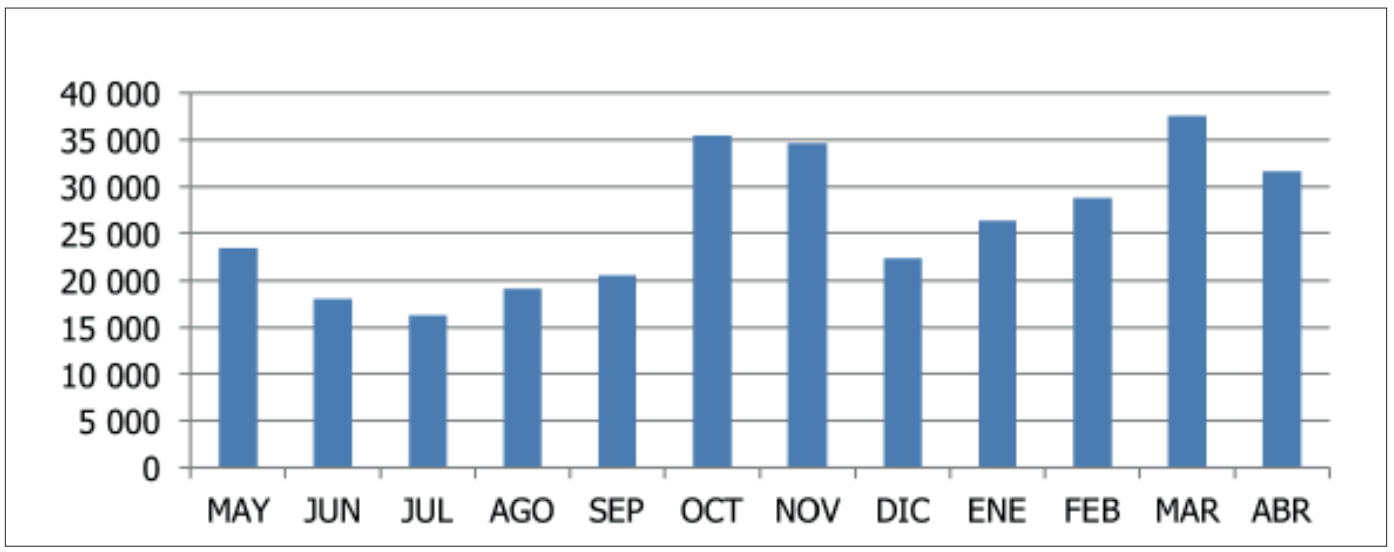

Fuente: Elaboración propia 
En la temporada 2019, con los datos hasta abril, como se muestra en la tabla 2, se ha producido un total de 319.106 salidas, lo que supone un incremento de 5.185 salidas respecto a la temporada anterior. Este incremento de jugadores, se reparte más o menos de manera uniforme entre el cliente local, el cliente visitante y el cliente longstay.

Tal y como se muestra en el gráfico 3, del total de salidas en la temporada 2019, el 30,27 \% corresponde al cliente local, el 56,70\% al cliente visitante y el 13,03\% al cliente longstay. Lo que significa que el número de jugadores aumenta en las tres procedencias, manteniéndose los porcentajes de reparto, con un ligero aumento en el cliente longstay.

Tabla 2: Numero de salidas por mes temporada 2018/2019

\begin{tabular}{|c|c|c|c|c|c|c|c|c|c|c|c|c|}
\hline May & Jun & Jul & Ago & Sep & Oct & Nov & Dic & Ene & Feb & Mar & Abr & Total \\
\hline 25.499 & 17.839 & 16.399 & 19.756 & 19.194 & 35.922 & 36.149 & 22.462 & 26.609 & 28.207 & 39.028 & 32.042 & 319.106 \\
\hline
\end{tabular}

Gráfico 3: Procedencia Salidas Temporada 2018/2019

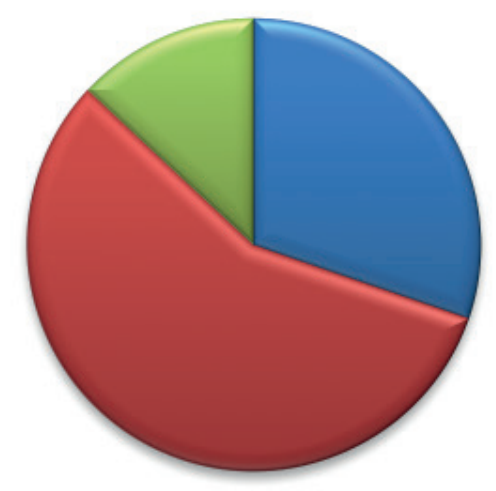

$\%$ local

$\%$ visitante

\% longstay

Fuente: Elaboración propia

Teniendo en cuenta las salidas del cliente visitante y el cliente longstay en la temporada 2019, podemos afirmar que han llegado a Almería aproximadamente 54.728 jugadores de golf que se han repartido por los 8 campos de la provincia, siendo los países de mayor procedencia, Reino Unido, Austria, Alemania, Bélgica y Países Nórdicos.

Gráfico 4: Numero de salidas temporada 2018/2019

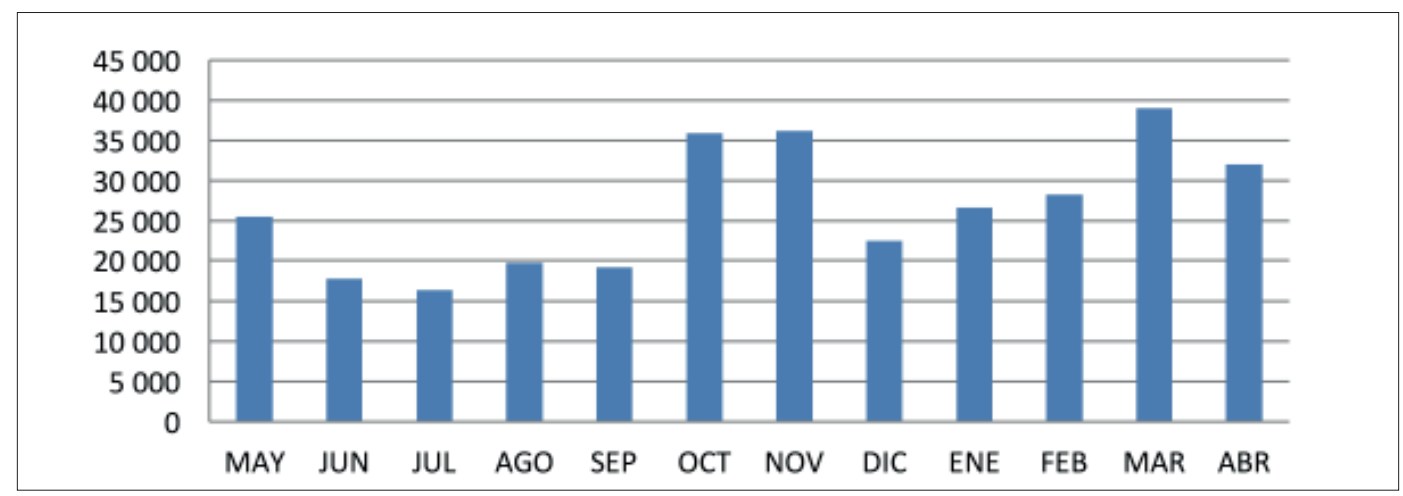

Fuente: Elaboración propia 
Si observamos los datos por meses, gráfico 2 y 4, vemos que la máxima ocupación se produce en los meses de octubre/noviembre y febrero/marzo/abril, coincidiendo con los meses de menor ocupación turística tradicional, lo que convierte al turismo de golf en Almería en una actividad complementaria al turismo de sol y playa, permitiendo que la planta turística permanezca abierta todo el año. Son los ingresos indirectos que genera este turismo en los meses de baja ocupación para la mayoría de la oferta turística, ingresos en el sector del transporte, hostelería, restauración y ocio en general.

La ventaja del turismo de golf es su capacidad desestacionalizadora, ya que el turista de golf viaja en temporada baja para el resto de la industria turística (Ortega, 1992).

Los gestores de las instalaciones señalan que el clima de la provincia de Almería, con temperaturas adecuadas para practicar este deporte en los meses de otoño e invierno, es el valor añadido para el turista de golf procedente de Europa que no puede jugar durante estos meses en su país de origen. Según los datos mostrados, podemos considerar que el turismo de golf es, además de necesario, estratégico para el sector turístico en la provincia de Almería, ya que dinamiza la economía de las zonas litorales de la provincia en los meses de baja ocupación.

\section{Perfil del turista de golf:}

De la información recogida de los responsables de las instalaciones, en contacto continuo con los clientes, se señalan las características de los tres tipos de cliente de golf que recibe la provincia de Almería.

Cliente local: es el cliente que reside en la provincia y juega habitualmente durante todo el año en el mismo campo de golf, elegido en la mayoría de los casos por cercanía a su residencia. Representa alrededor del $30 \%$ de las salidas anuales de todos los campos. Es un cliente asiduo que juega todas las semanas y hace uso con regularidad de todas las instalaciones anexas al campo de golf, como el campo de prácticas, la escuela de golf, la tienda de material de golf y la cafetería-restaurante del campo donde suele jugar. Habitualmente participa en los eventos deportivos como competiciones organizadas en su campo o en los campos cercanos.

Según el artículo que publica la Federación Española de Golf el 9 de enero de 2019 en su web en la sección de noticias, en Almería a 1 de enero de 2019 había 3.036 jugadores federados, siendo la tercera provincia con mayor ratio de jugadores/población de Andalucía y la única junto con Málaga donde se ha producido un aumento del número de jugadores federados con respecto al pasado año (RFEG, 2019).

Cliente visitante: representa casi el $57 \%$ de las salidas de todos los campos de golf de la provincia. El cliente visitante engloba:

- residentes en España

- turista vacacional

- turista de golf

El residente en España, es el jugador procedente de Europa, que reside en Almería o en provincias cercanas, como el litoral de Málaga, Murcia o Alicante. Generalmente forman asociaciones deportivas sin ánimo de lucro, las llamadas Golf Society para obtener mejores condiciones de juego en los campos de golf. Suelen jugar en grupo organizando competiciones a lo largo de todo el año en todos los campos de la provincia. También se incluye aquí el turista de golf nacional que aprovecha los fines de semana o días festivos del otoño e invierno para salir de su lugar de residencia y jugar en campos de golf de la zona sur de España. Almería está entre esas zonas visitadas con el único motivo de jugar al golf.

Turista vacacional: es el turista que viene de vacaciones a las zonas litorales de Almería en los meses de primavera y verano, cuando no trabaja la tour operación de golf. Su motivo del viaje no es jugar al golf. Viaja en familia o con amigos por ocio, recreo o diversión y si es jugador, visita al menos un campo de la provincia durante su estancia.

El número de salidas del turismo vacacional, principalmente las que se producen en el mes de agosto, ha experimentado un incremento progresivo en los últimos años y se estima que seguirá en alza una vez que se mejoren infraestructuras en general y oferta complementaria, que es lo que más valora este tipo de cliente. Este turista viaja atraído por el sol y playa, gastronomía, turismo deportivo, rural o urbano, lo que permite establecer sinergias entre todas las actividades que conforman la oferta turística en Almería, aumentando la capacidad de ofrecer al que visita la provincia un amplio abanico de posibilidades que hagan de su experiencia un motivo para volver a visitar y recomendar el destino Almería. 
Turista de golf: es el cliente visitante internacional cuyo único motivo del viaje es jugar al golf. Dentro de los clientes visitantes es la partida más importante por ser la más numerosa y la que no ha dejado de crecer en los últimos años. Representa el $87 \%$ de las salidas de los clientes visitantes. El turista de golf viene sólo los meses de otoño e invierno, cuando no pueden practicar este deporte en sus países de origen. Procede del norte y centro de Europa, principalmente de Reino Unido, Bélgica, Irlanda, Alemania, Austria y Países Nórdicos. Aunque la motivación para este tipo de turismo es la oferta de golf, también valora la cercanía a la costa, las infraestructuras de acceso, la seguridad del destino y la oferta complementaria, en especial la gastronómica.

Es un cliente que viene a través de la tour operación, la estancia media es de 6 días y suele viajar con amigos o en pareja. Se alojada en los hoteles cercanos a los campos o en los resorts de los que forma parte el campo de golf y la media de edad de este cliente es de 55 años.

Cliente Longstay: es el turista de golf procedente de los Países Nórdicos, cuya estancia en el destino es superior a 21 días. Representa el $13 \%$ de las salidas anuales. Es un cliente fiel al destino, en edad de jubilación, que realiza todos los años un viaje internacional para jugar al golf, recomendando el destino cuando llegan a su país de origen. Entre las características de este cliente se encuentran que viaja en pareja, se aloja en apartamento turístico a pie del campo de golf en el que juega durante toda su estancia, conoce el destino por experiencia propia, y la estancia media de este cliente es de 25 días, jugando una media de 19 veces. Suelen volver con amigos que también viajan en pareja, es decir, es un tipo de cliente con el que funciona el boca-oreja.

Valora principalmente el clima, poder jugar todos los días de su estancia, la oferta gastronómica y la cultural. Los gestores de los campos hacen referencia al aumento que se está produciendo en la duración de la estancia" En los dos últimos años entre un 15-20\% de las parejas están ampliando el periodo de estancia a 6 semanas para la siguiente temporada y la gran mayoría hacen su reserva antes de marcharse a su país de origen."

La información recogida muestra que existe un cliente procedente de Europa que llega a Almería con el único motivo de jugar al golf. Como hemos podido observar, además de las condiciones climatológicas idóneas y las instalaciones de golf, también valora la seguridad del destino España, las conexiones e infraestructuras y la oferta complementaria, especialmente la gastronómica.

\section{Mercado europeo de jugadores}

Según el informe estadístico elaborado en octubre de 2018 por KPMG, en Europa a final de 2017 había un total de 4.142.390 jugadores de golf, estando más del 50\% del mercado europeo de jugadores de golf concentrado en los siguientes cinco países: Inglaterra, Alemania, Suecia, Francia y Países Bajos. El primer lugar en número de jugadores lo ocupa Inglaterra, país de larga tradición golfística, sigue siendo el que más jugadores de golf aporta, el 15,83 \% del total de jugadores europeos, lo que supone 655.839 jugadores. Le sigue muy de cerca Alemania que en los últimos 10 años ha experimentado un rápido crecimiento, aportando al mercado el $15,57 \%$ de jugadores. Suecia es el país que más crecimiento de jugadores ha experimentado con respecto al año anterior y ha aportado el 11,31\% de jugadores europeos al mercado. Completan el 61,97 \% del mercado los países de Francia y Paises Bajos, con el $9,90 \%$ y el $9,36 \%$ de jugadores europeos respectivamente (KPMG, 2018).

Uno de los últimos estudios sobre turismo de golf en España, constata que la mitad de los viajes de golf realizados por ingleses y suecos son de carácter internacional y en Alemania, el 90\% de los destinos elegidos por los jugadores de golf se encuentran en el extranjero. En este escenario España se configura como el principal destino de golf en el extranjero de los turistas británicos, alemanes, y suecos, siendo el segundo destino elegido por los franceses, después de Marruecos (Gabinete de Estudios de la Cámara Oficial de Comercio, Industria, Servicios y Navegación de Alicante, 2016)

Del análisis del mercado europeo de jugadores se desprende que el gran número de jugadores que poseen países como Inglaterra o Alemania unido a la gran popularidad de este deporte en los países de la zona norte y centro de Europa, es el motivo para que estos países se hayan convertido en emisores de jugadores en la temporada de otoño e invierno cuando sus campos de golf están cerrados.

Los países del sur de Europa y de la cuenca mediterránea son los receptores de estos jugadores. La razón principal para elegir los destinos del sur durante el otoño e invierno es la búsqueda de condiciones climatológicas idóneas para poder jugar al golf y de una oferta de campos variada. Entre estos países receptores del turismo de golf, se encuentra España, como uno de los principales países que recibe 
a jugadores procedentes de Europa durante la temporada que va desde octubre hasta abril (Centro Euromediterráneo de conocimiento, innovación y formación turística, 2007)

En este sentido, cuando se visita el portal de Turismo de España, puede verse entre sus publicaciones que España es líder del turismo europeo de golf. La noticia, consultada en mayo de 2019, relata que cada año miles de personas lo eligen para practicar este deporte. (Portal Oficial de Turismo de España, 2019).

El destino principal dentro de este país es Andalucía, que fue elegida como destino europeo de golf del año en los Premios 2017 que concede la Asociación Internacional de Operadores de Golf (IAGTO). ${ }^{5}$ Con más de cien campos de golf, Andalucía es la número uno en instalaciones, en servicios y en la promoción y comercialización del golf (web oficial de turismo de Andalucía, 2018).

Andalucía se ha convertido en la Comunidad Autónoma de España líder en la recepción de este tipo de turistas, con el consiguiente aumento del número de campos de golf (Riquel y Vargas, 2012).

Así, actualmente el segmento del golf es uno de los más competitivos y de mayor impacto para la industria turística andaluza contribuyendo de manera muy significativa a romper la estacionalidad en el litoral andaluz, al mantener el sector hotelero abierto durante todo el año, siendo Andalucía un área receptora del mercado europeo, donde es imposible practicar este deporte durante los meses de otoño e invierno. Destaca en el destino Andalucía la provincia de Málaga, cuyo litoral junto con el gaditano Campo de Gibraltar conforma la famosa Costa del Sol, conocida en Europa como el destino Costa del Golf que cuenta actualmente con más de 70 campos de golf y ha conseguido una especialización turística en este segmento. Si bien, en los últimos años ha crecido el interés por otros destinos como Canarias, Comunidad Valenciana y Cataluña (Reyes Bazán, 2016).

A modo de reflexión, en Almería, al igual que sucede en la Costa del Sol o la Costa del Golf, la marca del destino, el sector del golf puede ser un importante elemento dinamizador del turismo que ofrece la provincia, ya que rompe la estacionalidad tan característica de este sector, cualifica la oferta turística y diversifica la actividad económica.

\section{Almeria un destino de golf}

Hasta hace unos años, el éxito de Almería como destino turístico descansaba fundamentalmente en el segmento tradicional de sol y playa, sin embargo, en los últimos años se asiste a una intensificación de la segmentación del mercado turístico, de forma que están surgiendo nuevos cauces de crecimiento del turismo frente al tradicional de sol y playa, que pueden ser aprovechados en la provincia. Entre estos nuevos segmentos turísticos se encuentra el turismo de golf (Aznar Sánchez, 2003).

Según los expertos en turismo, la capacidad de un área turística para ser un destino de golf depende de tener un mínimo de campos de golf que no estén a mucha distancia entre sí, que compongan una variada oferta con tarifas adecuadas a la tipología del campo, con infraestructuras, conexiones y otros atractivos que complementen la oferta de golf, además de unas condiciones climáticas que aseguren la práctica de este deporte durante todo el año (Centro Euromediterráneo de conocimiento, innovación y formación turística, 2007)

En virtud de todo lo expuesto anteriormente, podemos afirmar que Almería reúne las condiciones para ser un destino de golf. La oferta compuesta por ocho campos de golf, con proximidad y buena conexión por carretera entre ellos, unido a las condiciones climáticas de la provincia, con muchas horas de sol durante todo el año, permite que los jugadores de golf que llegan a Almería puedan disfrutar durante su estancia de diferentes experiencias de juego en diversos entornos, bien con vistas al mar o rodeados por montañas.

Sin embargo, del análisis del sector, se desprende que Almería como destino turístico de golf no es aún un destino consolidado, es un destino débil frente a otros cercanos como Costa del Sol, Costa Blanca o la región de Murcia. En definitiva un destino aún en vías de desarrollo.

Con la información recogida y los datos analizados, hemos profundizado en el análisis de las fortalezas y las debilidades de Almería como destino para la práctica de este deporte frente a otros ya consolidados.

Actualmente las fortalezas son principalmente, el clima y el precio. Almería es un destino más económico que los destinos cercanos como la Costa del Sol (RFAG, 2019) o la Costa Blanca (ACGCB, 2019). En la provincia el precio medio del green fee ${ }^{6}$ para el cliente visitante extranjero es entre un $25 \%$ y un $30 \%$ menos costoso que en los destinos de golf cercanos. En referencia al clima, Almería es una de las provincias de Europa con más horas de sol, lo que garantiza el juego durante prácticamente toda la estancia del cliente. 
El otro punto fuerte es que es un destino en pleno desarrollo, con una alta capacidad de adaptación a la demanda del cliente, frente a otros destinos ya consolidados con estructuras productivas más rígidas y con menos flexibilidad frente al mercado turístico continuamente cambiante.

Con respecto a las debilidades, cabe considerar como la más importante la deficitaria red de infraestructuras en general, que impide el acceso a la provincia en condiciones óptimas. El aeropuerto cuenta con un número muy reducido de vuelos internacionales y una escasa conexión con los países emisores del turismo de golf. En el año 2018 Almería ha sido el único aeropuerto de Andalucía que ha perdido pasajeros, quedándose por debajo del millón, concretamente 992.043 pasajeros lo que supone una caída con respecto al año anterior de 1,5\%. Actualmente, en la temporada de golf, los únicos vuelos directos con Europa existentes son con Bruselas, Dússeldorf y Londres (web oficial aeropuerto de Almería, AENA, 2019)

Los responsables de los campos de golf resaltan que la mayoría del turismo que reciben procedente de Irlanda, Austria o Países Nórdicos, llega a la provincia a través del aeropuerto de Málaga o Alicante, lo que hace que sea más fácil para el cliente elegir el destino Costa Blanca o Costa del Sol que posee un aeropuerto internacional y donde hay más de 70 campos con una amplia oferta complementaria.

Otra cuestión a mejorar es la oferta complementaria cercana a los campos de golf durante los meses de otoño e invierno, ya que la mayoría del sector hotelero y de restauración situados fuera del entorno de la ciudad, cierran sus puertas una vez finalizada la temporada de verano. Cabe destacar que para el jugador de golf es importante la infraestructura en general, demandando mejores conexiones dentro de la provincia y con las provincias limítrofes. Esta mejora se proyecta como un aspecto que facilitaría el desarrollo de actividades complementarias como la restauración, las visitas culturales e históricas, las fiestas tradicionales, los centros comerciales y de ocio, el turismo de aventura o de salud e incluso el traslado a otras provincias cercanas para visitar monumentos, museos o zonas con valor histórico y cultural.

La aproximación a la realidad muestra también la necesidad de cualificación de los recursos humanos que requiere el sector turístico en general y más específicamente el del golf. Es necesario dar respuesta a la incipiente demanda de profesionales provocada con la especialización de la oferta a medida que se produce el desarrollo en el sector.

Los principales implicados en el sector señalan que es necesario mejorar en general la percepción social del golf en la provincia para poder apostar por un turismo sostenible y consolidar Almería como un destino de golf.

"La sociedad en general debe ser consciente que esta actividad aporta valor a la economía de la provincia, rompiendo la estacionalidad del sector turístico. Además es un deporte saludable, accesible a personas de distinto poder adquisitivo y de cualquier edad, siendo una actividad controlada y respetuosa con el medio ambiente".

Por último, los datos analizados indican la falta de apoyo al destino Almería de la administración pública en general. En el sector turístico, por delante de las administraciones, siempre han ido los empresarios del sector, y en el caso de Almería, esta afirmación es aún más cierta (Fernández-Revueltas, 2005). Teniendo en cuenta el apoyo institucional en otros destinos como la Costa del Sol, Canarias o Baleares donde las administraciones públicas se implican y dedican una parte de sus recursos a la promoción exterior, se muestra que la provincia de Almería va con retraso en este aspecto, aunque hemos podido comprobar que en los últimos años esta tendencia está cambiando, y ya existen acciones por parte del Servicio Provincial de Turismo de la Diputación de Almería promocionando el turismo de sol y playa con la marca Costa de Almería. Este turismo de sol y playa conlleva una alta estacionalidad, concentrando las pernoctaciones en los meses de junio a septiembre. Así, Almería ha conseguido una mayor conexión área con Europa en los meses estivales (AENA, 2018), sin embargo, a modo de discusión nos preguntamos qué sucede con el sector turístico el resto del año y qué sucede con el turismo que no es Sol y Playa.

Desde la visión global del turismo de golf en Almería obtenida con este estudio consideramos que hay una gran labor a realizar por parte de todos los agentes públicos por el sector turístico en Almería. 


\section{Asociación de campos de golf de almería}

Los datos analizados justifican el beneficio para la provincia de consolidar el destino, siendo vital unir esfuerzos de todas las empresas involucradas en el sector del golf en Almería. Los responsables de los campos de golf manifiestan que desde hace varios años son conscientes de la necesidad de crear una asociación de campos de golf que ayude a situar el destino Almería como uno de los principales destinos en Europa para la práctica del golf y en uno de los ejes de la industria turística de la provincia. La experiencia en otras zonas con el mismo denominador común es muy positiva, como por ejemplo la asociación de campos de golf de la Costa Blanca.

En efecto, el estudio del sector muestra que la consolidación del destino Almería requiere dar una respuesta conjunta y adecuada a diferentes aspectos, como formar profesionales en el sector, mejorar la cantidad y calidad de la oferta complementaria durante los meses de otoño e invierno, concienciar sobre lo que representa el sector para el desarrollo de la provincia, realizar una comercialización conjunta y conseguir el apoyo institucional para llevar a cabo una acción promocional de la imagen global que se proyecta en los destinos internacionales de la oferta de golf en Almería.

La asociación de campos de golf de Almería (ACGA) nace en 2019, con el objetivo de consolidar Almería como un destino turístico de golf. Entre las acciones a llevar a cabo se encuentran la de promocionar y transmitir las ventajas competitivas que tiene la provincia, desarrollar y potenciar una cultura colaborativa en la oferta de instalaciones para proyectar una imagen unificada y fuerte de Almería como destino de golf en Europa, promover iniciativas de colaboración con el resto del sector turístico para crear una oferta conjunta con restauración, alojamiento, transporte, cultura, ocio, etc. Asimismo, conseguir el apoyo institucional para llevar a cabo un plan de promoción exterior que incluya a toda la industria turística, para mejorar las conexiones e infraestructuras de acceso a la provincia, y en definitiva para facilitar y apoyar la actividad turística en la provincia de Almería.

\section{Conclusiones}

Con el acercamiento a la realidad del turismo de golf en Almería y fruto del estudio de las diferentes consideraciones recogidas de cada uno de los actores involucrados en el sector, extraemos las siguientes conclusiones.

Se ha mostrado que existe un mercado europeo de jugadores, en el que España se ha posicionado como uno de los principales países receptores, destacando Andalucía como principal destino elegido por los países del centro y norte de Europa, para jugar al golf durante el otoño e invierno.

La razón principal para elegir los destinos del sur es la búsqueda de condiciones climatológicas idóneas para practicar este deporte y una oferta de campos variada. Este turismo de golf consigue romper la estacionalidad que satura los destinos turísticos los meses de verano y los deja vacíos durante el otoño e invierno, dinamizando todo el sector turístico, consiguiendo que permanezca activo durante todo el año (Babinger, 2012).

En el conjunto del destino Andalucía se encuentra la provincia de Almería que con una oferta de ocho campos de golf, es un destino de turismo de golf en pleno desarrollo. Las cifras analizadas muestran que en los meses de octubre/noviembre y febrero/marzo/abril se produce el aumento de salidas en los campos de golf de jugadores procedentes principalmente de Reino Unido, Bélgica, Irlanda, Alemania, Austria y Países Nórdicos, dinamizando el sector turístico de la provincia en la tradicional temporada baja, gracias al valor añadido del turismo de golf, su capacidad desestacionalizadora.

Los datos obtenidos manifiestan el crecimiento y por tanto la importancia que este subsector turístico está adquiriendo en Almería, por lo que entendemos que se hace necesario una atención especial y una profundización en el conocimiento de todos aquellos aspectos más relevantes que inciden directamente o indirectamente en su desarrollo.

Entre estos aspectos cabe destacar la necesidad de mejorar las conexiones e infraestructuras, la cantidad y calidad de la oferta complementaria durante los meses de otoño e invierno, la cualificación de los recursos humanos y el cambio en la percepción social negativa del golf, demostrando con datos que puede ser un turismo generador de riqueza en la provincia.

En este proceso de desarrollo del turismo de golf, la recién estrenada ACGA nace con el objetivo de consolidar Almería como destino de golf, impulsando la comercialización conjunta de la oferta, la imagen global que se proyecta en Europa y creando sinergias con el resto del sector turístico para conseguir 
que Almería como provincia sea capaz de crear una oferta turística en conjunto más novedosa y de más calidad, acorde a las necesidades del turista de hoy, atendiendo a un mercado cada vez más exigente.

Hoy es necesario tener en cuenta una demanda informada, exigente y cambiante para la cual temas como calidad, sostenibilidad y competitividad, forman parte de los criterios para elegir destino (Canales Ronda y Hernández Fernández, 2019).

Considerando todo lo expuesto anteriormente se indica que el desarrollo de este turismo debe hacerse desde el punto de vista de la sostenibilidad.

En este sentido, The Royal and Ancient, organismo cuyos estudios y directrices son de utilidad para las federaciones y clubes de golf de todo el mundo, define la sostenibilidad de los campos de golf como "Optimizar la calidad del campo de golf en armonía con la conservación de su entorno natural bajo gestión económicamente acertada y socialmente responsable" (The Royal \& Ancient Golf Club de St.Andrews R\&A, 2017). Y la organización mundial de turismo define el concepto de desarrollo sostenible del turismo como "El turismo que tiene plenamente en cuenta las repercusiones actuales y futuras, económicas, sociales y medioambientales para satisfacer las necesidades de los visitantes, de la industria, del entorno y de las comunidades anfitrionas" (UNWTO, 2019)

En consecuencia y desde el análisis realizado, se expresa la conveniencia de establecer las claves para un desarrollo sostenible del turismo de golf en la provincia que ayude a situar el destino Almería como uno de los principales destinos en Europa para la práctica de este deporte y en uno de los ejes de la industria turística, a través de estrategias a medio y largo plazo de desarrollo sostenible, realizando una correcta planificación (Rodriguez, 2009), apoyándose en la idea de que el turismo de golf es un gran motor de desarrollo, de creación de riqueza, bienestar y empleo y en la necesidad de preservar el entorno medioambiental, paisajístico, cultural y social. En definitiva el desarrollo turístico en clave de sostenibilidad.

La consideración de la dimensión territorial y medioambiental, es determinante para garantizar la competitividad del destino (Espejo Marín, 2004)

Por último, por los datos aquí presentados, se expresa la importancia de prestar mayor atención por parte de los agentes públicos al turismo de golf, valorando la capacidad desestacionalizadora de este sector y por tanto el valor añadido a la industria turística de la provincia. Se considera indispensable un esfuerzo por parte de la Consejería de Turismo y Deportes, la Diputación Provincial, Ayuntamientos y Universidad, implicándose en la labor de concienciación positiva de este turismo, en la mejora de infraestructuras, accesos, señalización y en la promoción del destino entendiéndolo como una inversión que a largo plazo origina beneficios en el sector turístico y el desarrollo de la provincia.

Del análisis del sector constatamos que Almería cuenta con una completa oferta de campos de golf, capaz de hacer sentir al visitante diferentes experiencias, una gran variedad de establecimientos hosteleros, empresas turísticas de diversa índole, una adecuada oferta gastronómica, y un clima para practicar este deporte al aire libre los 365 días del año. En definitiva Almería reúne las condiciones para ser uno de los principales destinos de golf en Europa.

\section{Bibliografía}

Asociación de Campos de Golf de la Costa Blanca y Comunidad Valenciana (ACGCB). (2019). https:// www.golfcostablanca.org/noticias/ (acceso 22/01/2019)

Aznar Sánchez, J.A. (2003). Análisis estructural del sector turístico en Almería. Cuadernos de Turismo,11,16-17.

Babinger, F. (2012). El golf en España: la concentración social y territorial de un fenómeno que trasciende ampliamente lo deportivo. Ería, 88, 185-197.

Canales Ronda P. y Hernández Fernández A. (2019). La actividad comercial en las empresas turísticas. Cuadernos de Turismo, 43, 249-269.

Centro Euromediterráneo de conocimiento, innovación y formación turística. (2007). El producto turístico del golf en los países del mediterráneo.

Espejo Marín, C. (2004). Campos de golf y medio ambiente, una interacción necesaria. Cuadernos de turismo, 14, 67-112

Fernández-Revueltas Pérez, L. (2005). 25 Años de "Costa de Almería” y ¿ahora qué? En J.Molina (Ed.), La Economía de la provincia de Almería (pp.365-412). Almería, España: Caja Rural Intermediterránea Cajamar

Ferreres Bonfil, JB. (2014). Turismo de Golf. En G. Sánchez (Ed.) 20 Años de la actividad turística en España. Barcelona, España: AECIT 
Gabinete de Estudios de la Cámara Oficial de Comercio, Industria, Servicios y Navegación de Alicante. (2016). Impacto económico del sector del golf en la provincia de Alicante.

García Lorca, A.M. (2007). Reflexiones sobre el modelo de turismo de golf en un litoral árido: Almería. Paralelo 37, 19, 209-224

KPMG The European Golf Course Owners Association. (2018). Golf Participation Report for Europe. https://assets.kpmg/content/dam/kpmg/xx/pdf/2018/11/golf-participation-report-for-europe-2018.pdf (Acceso el 10/07/2019)

Organización Mundial de Turismo (UNWTO) (2018). https://www.unwto.org/es/desarrollo-sostenible (acceso 29 de marzo de 2018) Ortega Martínez, E. 1992: La economía del golf: su evolución en el mundo y en España. Estudios turísticos, 144, 19-40

Portal Oficial de Turismo de España. (2019). https://www.spain.info/es/que-quieres/deportes/golf/ (acceso el 16/05/2019)

Real Federación Española de golf (R.F.E.G.) (2019). http://www.rfegolf.es/Noticias/NewsDetails. aspx?NewsId=9623 (acceso 24/05/2019).

The Royal \& Ancient Golf Club de St.Andrews ( R\&A). (2017). http://clubmanagerspain.com/reportajes/ clubes-deportivos-y-medioambiente/151-st-andrews-y-el-golf-sostenible.html (acceso 27/2/2018)

Reyes Bazán. (2016). El campo de golf como instrumento de regeneración y protección

del medio ambiente. En F. Bombillar (Ed.), Diferentes perspectivas del derecho deportivo en Andalucía, libro homenaje al profesor Rafael Barranco Vela (pp 47-59). España: Comares

Riquel Ligero, F.J y Vargas Sánchez, A. (2012). Legitimidad social versus desempeño en

las políticas de responsabilidad social mediambiental de los campos de golf andaluces. Visión de Futuro Año 9,16 (2).

Rodríguez Vaquero, J. (2009). Turismo urbano y sistema territorial Almería, modelo emergente. Nimbus, 23-24, 171-181

Serrano Gómez,V. (2013). Evolución de la práctica del golf, características y dimensión económica. Revista española de educación física y deportes, 403,63-80

Web Oficial Aeropuerto de Almería. (2018). http://aena.mobi/m/es/aeropuerto-almeria/almeria.html (acceso 30/04/2019)

Web Oficial Aeropuerto de Almería. (2019). http://www.aena.es/csee/Satellite?c=Page\&cid=111358247 6711\&pagename=Estadisticas\%2FEstadisticas (acceso 22/09/2019)

Web oficial de turismo de Andalucía. (2018). https://www.andalucia.org/es/andalucia-destino-europeo-de-golf-del-ano (acceso 13/2/2018)

\section{Notas}

1 Real Federación Española de Golf (RFEG), es el organismo máximo responsable a nivel del estado español para la práctica del deporte del golf. Es obligatorio que se federen en este organismo todos los clubes de Golf y los jugadores que practican este deporte.

2 Real Federación Andaluza de Golf (RFAG), es la Federación Autonómica, organismo colaborador de la Real Federación Española de Golf responsable de la práctica del deporte de golf dentro de la Autonomía de Andalucía.

3 La Organización Mundial del Turismo (UNWTO) es el organismo especializado de las Naciones Unidas encargado de la promoción de un turismo responsable, sostenible y accesible para todos.

4 The Royal \& Ancient (R\&A) es el organismo que regula las Reglas del Golf en el mundo junto a la United States Golf Association (USGA). Los estudios y directrices del R\&A, ubicada en St. Andrews, Escocia, son de utilidad para las federaciones y clubes de golf de todo el mundo. Ambos organismos comparten la gobernanza del golf en el mundo. Cada organización tiene su propia jurisdicción, la USGA gobierna en Estados Unidos y México y el R\&A en el resto del mundo. La jurisdicción del R\&A abarca 143 organizaciones de golf amateurs y profesionales, regulando el juego de más de 30 millones de jugadores en más de 126 países.

5 La IAGTO es la Asociación Internacional de Operadores de Golf que cuenta en la actualidad con más de 650 tour operadores especializados en el segmento golf, procedentes de 61 países, que controlan la comercialización de aproximadamente el $87 \%$ de los paquetes vacacionales de golf del mundo.

6 Green fee: es el precio estipulado por los campos de golf para poder jugar en ellos. El mismo puede variar según el día de la semana, hora, nivel, y si el jugador es miembro o no del club (Serrano, 2013)

Recibido:

$30 / 11 / 2019$

Reenviado:

$07 / 06 / 2020$

Aceptado:

$28 / 07 / 2020$

Sometido a evaluación por pares anónimos 